\title{
Calcineurin Subunit B Type 1
}

National Cancer Institute

\section{Source}

National Cancer Institute. Calcineurin Subunit B Type 1. NCI Thesaurus. Code C38529.

Calcineurin subunit B type 1 (170 aa, $19 \mathrm{kDa}$ ) is encoded by the human PPP3R1 gene.

This protein plays a role in both calcineurin regulation and apoptotic signaling pathways. 